\title{
Using a Grounded Theory to Determine the Motivational Factors of Engi- neers' Participation in Public Policy
}

Mrs. Sarah Bouazzaoui, Old Dominion University

Sarah Bouazzaoui is a Ph.D. candidate and an adjunct instructor at Old Dominion University. Her research interests include Engineering Ethics, socio-political engineering, Motivation theory, Leadership, and System complexity. Her email address is sbouazza@odu.edu. 


\title{
Engineers' Motivation to Influence Public Decision Making: A Grounded Theory Approach
}

\author{
Sarah Bouazzaoui \\ Charles B Daniels, PhD \\ Engineering Management and Systems Engineering \\ Old Dominion University
}

\begin{abstract}
In the United States of America, public policies and public decision making associated with the engineering field are set by individuals who does not possess expertise and knowledge to carry out these tasks [1]. Most of decision makers are lawyers and social scientists, not engineers [2]. The purpose of this paper is to analyze the various factors which either encourage or inhibit engineers from influencing and participating in public policy. In this study, a grounded theory approach will be followed, data will be collected using semi-structured interviews and analyzed to develop a theory of research direct toward increasing the motivation of engineers to participate in public policy.
\end{abstract}

\section{Introduction}

Society deals with various ongoing issues including climate change, underwater drilling, self-driving cars...etc. These issues have significant technical elements that require a disciplined approach to their definitions, risk analysis, and optimal solutions. Engineers have the ability and responsibility to help public decision maker in carrying these tasks. As communicated by Robert S. Walker, former U.S. Representative and former Chair of the House Science Committee noted, "Engineers can positively influence the policy process by openly and publicly enunciating the role...". Their practical advice and input are vital to enhancing the quality of the decisions made at the different levels of the government, to set efficient public policies. Unfortunately, there are virtually no engineers or scientists participating in policies and decisions related to these phenomena. Only non-technical-oriented individuals, who do not possess the required expertise and knowledge, carry out these tasks [1]. Even though some engineer's members of organization, such as ASCE, work for government organizations and provide advices to policy makers, they are not involved in policy related decisions [3].

Accordingly, in the seminal report, ' Engineering for a Changing World: A Roadmap for the Future of Engineering Practice, Research, and Education [the Millennium Project, The University of Michigan 2008]' ' Dr. James J. Duderstadt stated, ',...The absence of engineers from either the leadership roles of business and government or the primary debates over the problems of our times poses a significant threat to society in an increasingly technological world...'. The need for engagement and involvement by engineers is of great significance for setting sound public 
policy and monitoring complex technical issues in the society. However, there remains a dearth of research in this area that needs to be studied.

The objective of this paper is to fill these gaps and contribute to the engineering education research. Based on the well-known Motivation-Opportunity-Ability (MOA) framework; concerned about identifying factors that impact message elaboration and message-evoked thinking [4]; a successful involvement of engineers needs to have three factors: motivation, opportunity, and ability. So far, most research bridging the gap between engineering and public policy has focused on opportunity and ability factors. Studies of opportunity seek to shed light on the possibilities offered to engineers to get involved in public policy, for instance, advocacy [5], while studies of ability seek to investigate the capabilities engineers need to participate in public policy making. For example, communication [6,7] and interdisciplinary work [8] have been considered as major elements contributing to engineers' ability in participating in public policy. To date, the motivation factor, understood as the extent to which persistent effort is directed toward a goal [9] remains largely unexplored. Specifically, this study was motivated to answer the following question: what inspires Engineers to influence and participate in the decision-making process? If not, what could be the reason?

\section{Methodology}

Given that there remains ambiguity around the "how" and "what questions related to the engineers influence on public policy, grounded theory was considered the proper approach. The GT method was first coined by Glaser and Strauss (1967) in their seminal work "The Discovery of Grounded Theory" as a reaction against the extreme positivism that had permeated most social research [10]. Since its introduction, several other versions by the co-originators followed, which developed and debated the GT method [11, 12]. Grounded theory is defined as "the systematic generation of theory from data acquired by a rigorous research method" p.3 [13]. Along similar lines, Martin and Turner (1986) defined GT as "an inductive, theory discovery methodology that allows the researcher to develop a theoretical account of the general features of a topic while simultaneously grounding the account in empirical observations or data" [14]. Therefore, a basic tenant of GT is that "all is data", where the researcher needs to constantly compare data to generate categories and the relationship among them. Figure 1 illustrates the steps of grounded theory and will be explained in the method and data collection method section.

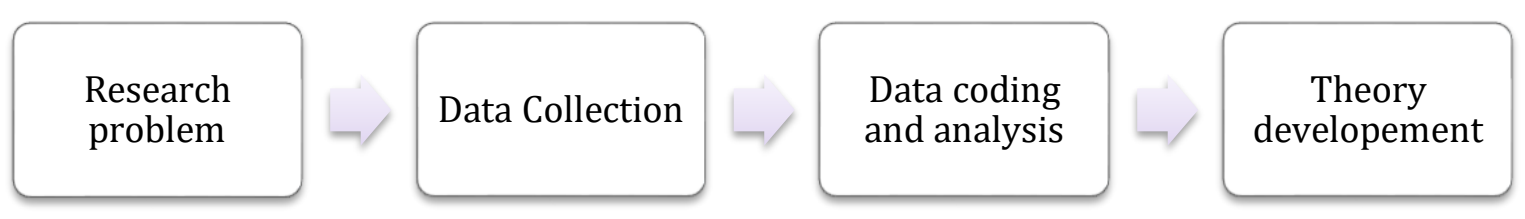

Figure1: Grounded Theory Stages.

This method enables the identification of general concepts, the development of theoretical explanations that reach beyond the known, and the providing of new insight into a variety of 
experiences and phenomenon [15]. The proper use of GT suggests that the researcher must be able to understand various perspectives and to be able to construct reality through interpretation of those perceptions.

\section{Method and data collection}

After getting an Institutional Review Board (IRB) approval from Old Dominion University, the data was carried out through a 5-month period starting March 1st, 2017 with participants that have a minimum of a bachelor's degree in engineering and at least 2 years of work experience. To ensure respondents' confidentiality, the names of participants will not be revealed the researcher will assign specific titles, as "Engineer 1", "Engineer 2" to respondents, and only these titles will appear in the result section. The purpose of the interviews was to understand the factors encouraging engineers to participate in public decision making and the obstacles they are facing.

One of the essential aspects in the data collection phase in the GT research process is sampling. Researchers must not randomly select cases but rather should do it incrementally following a theoretical sampling logic. This said, the researchers select an initial case, and on the basis of the data collected and the emerging theory, they select additional cases. As stated by Strauss and Corbin (1990, p. 192), "unlike the sampling done in quantitative investigations, theoretical sampling cannot be planned before embarking on a grounded theory study. The specific sampling decisions evolve during the research process itself' [12]. The theoretical sampling process continued until the point of theoretical saturation, which means that the researcher stopped interviewing engineers when no new relevant data emerges and the relationship between the different categories is established [16].

A total of 13 semi-structured interviews; open-ended questions; were conducted. The duration of each interview ranged from 30 to 45 minutes. Following is a list of questions asked within the interview:

- What avenues does an Engineer have, to get more involved in public policy issues?

- Why might an Engineer choose be involved in public policy issues?

- What are the benefits to an engineer who is participating in public decision-making?

$\circ$ What are they?

- Why might an Engineer choose to not be involved in the political process?

- Why might an Engineer should be attracted the political process?

- How can an Engineer be encouraged to participate in the public decision process?

- Are there any challenges facing an Engineer in public decision-making, under the American political landscape? What are they?

The interviews were tape-recorded and transcribed to preserve the entirety of statements and allow high reliability of the data [17]. Transcripts were imported into QSR NVivo 10 for coding. The coding process followed the coding approach developed by Miles and Huberman (1994) including open, axial, and selective coding [18]. During the open coding, a list of 50 codes emerged from the interviews which was highlighted by Merriam (2009) "At the beginning of an inquiry, this list is likely to be fairly long because you do not yet know what will surface across the rest of the data. You also will not yet know which groupings might be subsumed under others" $p$. 180 [19]. During the axial coding, key phrases were conceptualized, and were grouped based on 
the similarities to create the main categories then integrated to form a theory in the selective coding stage.

The following table summarizes this process:

\begin{tabular}{|l|l|l|l|}
\hline & open coding & axial coding & selective coding \\
\hline$\underline{\text { codes }}$ & 50 codes & 4 codes & 4 main themes \\
\hline$\underline{\text { activities }}$ & $\begin{array}{l}\text { constant comparative } \\
\text { analysis }\end{array}$ & $\begin{array}{l}\text { themes } \\
\text { generation }\end{array}$ & $\begin{array}{l}\text { relationship between } \\
\text { codes }\end{array}$ \\
\hline
\end{tabular}

Table1: Coding Process

These categories will be explained in the discussion section.

\section{Results and discussion}

Several theories attempt to explain motivation and the factors affecting it. The most popular explanations were suggestd by Abraham Maslow (Maslow, 1987), Frederick Herzberg (1986), and Clayton Alderfer (1977), within different contexts excluding the engineering and public policy field. Thus, this present study is the first to explore in depth the factors impacting engineers' motivation to influence public decision making (Figure 2 illustrates the findings). The key drivers identified are personal satisfaction, leadership, power, relevance, and education.

\section{$\underline{\text { Personal satisfaction }}$}

Personal satisfaction emerged as one of the factors motivating engineers to influence public decision making. Engineer 1 stated that "I would participate just to think of oneself as being important, to make my voice heard". This can be explained by ego reasons driving his motivation. Furthermore engineer 2 mentioned "I believe that I have valuable skills that can make governmental organization make better decision". This clarifies that this participant has a strong self-esteem and confidence in his ability to influence governmental decision. In psychology, selfesteem is interrelated with motivation [20], where an individual with high self esteem tend to be more motivated to do more whether in his personal or professional life, it is a growth need that impacts his motivation [21]. Along similar lines, Eccles and Wigfield (2002) stated that confidence in someone's ability increases his motivation to complete a task [22]. Thus, we propose the following:

\section{Proposition 1: Self-satisfaction is a factor that impacts engineer's motivation}

Education: engineering and public policy

Data indicated that most of the engineers are not involved in public decision making due to their lack of knowledge related to this discipline. 9 Participants out of 13 mentioned that introducing engineering students to public policy concepts is important. One noted remark from Engineer 10 who stated "I reflect for myself, Am I qualified enough to voice my concern? Lack of education 
when it comes to policy making. I have to ask two to three times of how can I bring this attention with comparing notes of the best way to bring my attention. It may be for those who are using the language for policy making but .........". Along these lines, engineer 2 mentioned "Even though I have the technical skills, I prefer to stay away from public policy because I am not familiar with public policy process". This proves that one of the obstacles of engineer's participation and influence is the lack of public policy knowledge. By reviewing engineer's education curriculums, in the USA educational system, engineers are not exposed to any course related to public policy. The integration of public policy courses into engineer's education is vital, especially that engineers recognize that the technical details matter in many policy issues. To further illustrate this point, we refer to studies discussing the relationship between knowledge and performance. Performance within a specific field is impacted by having knowledge about this domain [23]. Weitz et al. (1986) found that sales person who are knowledgeable about business domain, practice sales effectively [24]. Along similar veins, in the context of education, Tai-Seale's study demonstrated student's participation in classrooms in associated to their preparation and familiarity with the subject [25]. Therefore, we suggest the following:

Proposition 2: If engineers are knowledgeable about public policy, they will be more motivated to participate in public decision making.

Leadership \& Power

Leadership emerged as the final construct of motivation. In the literature studying organizational behavior, various views associated leadership to personal capability, as well as the environment in which the person find himself [26]. In the context of engineering, leadership is important as it has become necessary to make changes in an environment where there is growing interdependence between technology, society, and public policy. Accordingly, this change can only come about if engineers take an active role and assume leadership positions [27] by possessing leading change main features [28]. Engineer 2 for example stated 'I don't see engineers being in that role because generally engineers do not attain the same level in executive leadership", engineer 5 specified that "To influence public decisions, engineers should get in decision-making positions or government positions, they should act as leaders", engineer 6 also stated that "The lack of influence is related to the fact that most of the decision makers are not engineers, but from other background. These people are leaders who have more power, and even if they get some assistance from engineering organizations, they have the last say". This participant has associated the influence to the position power, which was discussed by scholars in other domains. In the business field for example, Smith et.al (2008) argued that when an individual has a position of power [29], he does more effort and feels more confident making decisions related to complex issues. Considering the government as a public organization, we may propose the following:

Proposition 3: The combination of both leadership and power impacts the motivation of engineers to influence public decision making.

\section{Theoretical generation}


Through an inductive analysis of the data, a theory used to identify the factors impacting the motivation of engineers' influence on public policy has been developed. The development of the framework was the result of the different themes and categories that emerged from the interviews. Figure 2 illustrates the Motivational Factors in Decision Making Influence

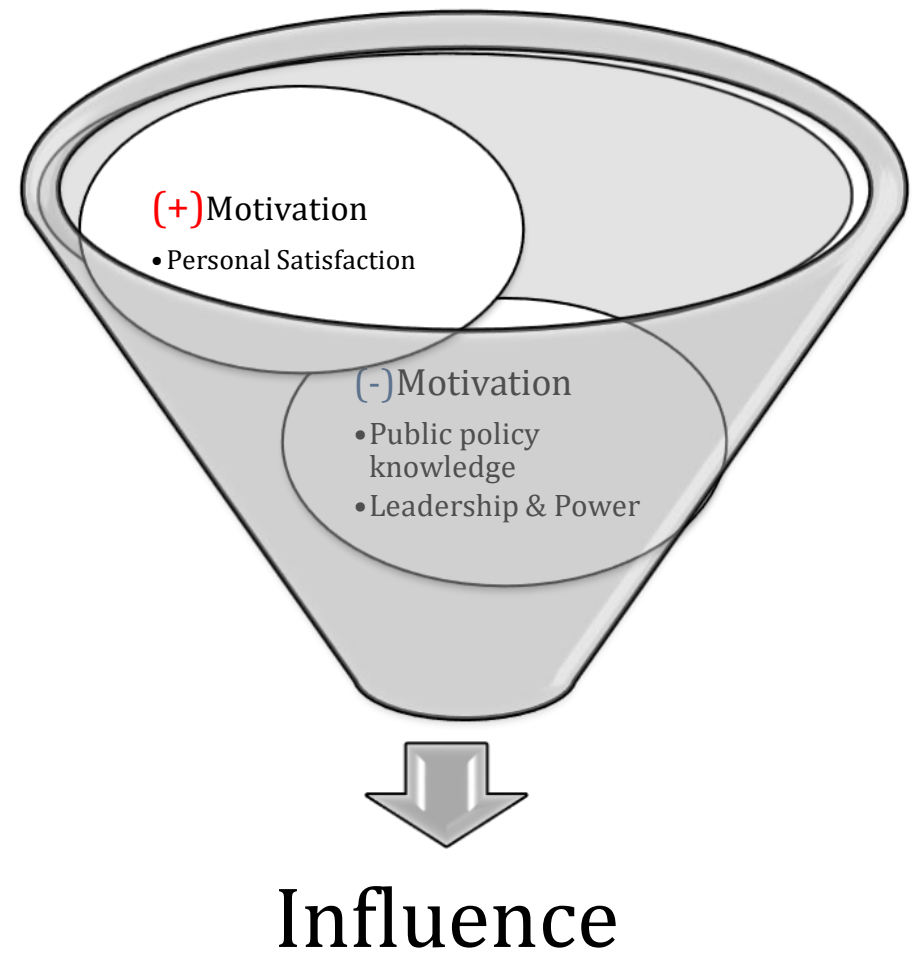

Figure 2: Motivational Factors of Engineers in Public Decision Making

Personal satisfaction, relevance, education, leadership are factors that have a strong impact on the direction of engineer's motivation, and consequently their behavior to influence public decision making

\section{Conclusion}

The study contributes to the literature in three important ways. First, it bridges the gap between engineering and public policy-making research. Second, the study extends to use of the grounded theory focusing on engineers' influence on public policy leading to the construction of a new motivational theory. Lastly, this study will also contribute to the research methodologies in engineering where grounded theory is of limited use. In fact, inductive research should be improved in areas related to engineering, such as decision making, and complex systems issues.

\section{Limitations of the study}


Although the GT method has been laudable for the insights it brought to various domains, it has been subject to several criticisms alike. One criticism was related to the philosophical divergence between the originators of the GT in developing their original concepts [30;31]. Moreover, the issue of hypothesis verification has been subject of on-going debate. While Glaser posits that the aim of GT is to generate hypothesis not to test them, Strauss and Corbin (1990) assert that verification is an integral part of the GT process itself. Furthermore, scholars criticized the GT method for its methodological deviations pertaining to the application of quantitative canons of rigor to GT [32]. Those canons although useful, they must be redefined to fit the realities of GT research and the complexities of social phenomena (Corbin and Strauss, 1990). Another shortcoming of the GT is referred to as premature closure, which means that the researcher fails to develop abstract concepts that are the essence of the emerging theory [32,31]

Furthermore, Scholars argue that the fact the researchers using grounded theory bring their own views and biases into the research which may affect its credibility [33,34]. This explains why constructive grounded - using grounded theory as well as a theoretical model- to guide the researchers' inquiry. Constructivist grounded theorists "do not attempt to be objective in their data collection or analysis, but instead seek to clarify and problematize their assumptions and make those assumptions clear to others" p. 212 [35].

This is not to say that the GT is not worth retaining or using in the investigation of phenomenon, but those elements should be handled properly and taken into account during the research design. The researcher should have a theoretical sensitivity with regards to existing literature and theory. Furthermore, the research design should emphasize the importance of constant comparison for continued review of assumptions and develop abstract conceptualizations throughout the entire research process to ensure theoretical generalizability.

\section{Bibliography}

[1]. Davis, L. A., Gibbin, R. D., et al. (2002). Raising public awareness of engineering. National Academies Press.

[2]. Rhode, D. L. (2013). Lawyers as Leaders. Oxford University Press.

[3]. ASCE Rapport. state government relation manual. retrieved from: https://www.asce.org/uploadedFiles/Issues_and_Advocacy/Advocacy_Programs/Content_Pieces/stategovernment-relations-manual.pdf

[4]. Hallahan, K. (2001). Enhancing motivation, ability, and opportunity to process public relations messages. Public Relations Review, 26(4):463\{480.

[5]. Kilpatrick, D. G. (2000). Definitions of public policy and the law. National violence against women prevention research center.

[6]. Dunn, K. (2009). The case for leadership skills courses in the engineering curriculum. In American Society of Engineering Education (ASEE) Midwest Section Conference.

[7]. Tull, K. and Jones, S. (2006). A sophomore-level engineering and public policy course required for ba engineering majors at lafayette college. American Society for Engineering Education.

[8]. Russell E, Marshall PP, Tramba A. (2006). Public Policy and Engineering Design: A Creative Partnership In Engineering Education. American Society for Engineering Education

[9]. Nader, R. (1988). Leadership and motivation. retrieved from http://www.tcii.gov.nl.ca/regionaldev/ccb/leadership/ccb_leadershipguide.pdf 
[10]. Suddaby, R. (2006). From the editors: What grounded theory is not. Academy of management journal, 49(4), 633-642

[11]. Strauss, A. L. (1987). Qualitative analysis for social scientists. Cambridge University Press.

[12]. Corbin, J. M., \& Strauss, A. (1990). Grounded theory research: Procedures, canons, and evaluative criteria. Qualitative sociology, 13(1), 3-21.

[13]. Glaser, B. G. (1998). Doing grounded theory: Issues and discussions. Mill Valley, CA: Sociology Press.

[14]. Martin, P. Y., \& Turner, B. A. (1986). Grounded theory and organizational research. The journal of applied behavioral science, 22(2), 141-157

[15]. Corbin, J., \& Strauss, A. (2015). Basics of qualitative research: Techniques and procedures for developing grounded theory. Sage publications

[16]. Strauss, A., \& Corbin, J. M. (1990). Basics of qualitative research: Grounded theory procedures and techniques. Sage Publications, Inc.

[17]. Gray, D. E. (2013). Doing research in the real world. Sage.

[18]. Miles, M. B., \& Huberman, A. M. (1994). Qualitative data analysis: An expanded sourcebook. sage.

[19]. Merriam, S. B. (2009). Qualitative research: A guide to design and implementation. SanFrancisco, CA: Jossey-Bass.

[20]. Maslow, A., \& Lewis, K. J. (1987). Maslow's hierarchy of needs. Salenger Incorporated, 14, 987.

[21]. Alderfer, C. P. (1977). A critique of Salancik and Pfeffer's examination of need-satisfaction theories. Administrative Science Quarterly, 658-669.

[22]. Eccles, J. S., \& Wigfield, A. (2002). Motivational beliefs, values, and goals. Annual Review of Psychology, 53, 109-132

[23]. Anderson, J. R. (1982). Acquisition of cognitive skill. Psychological review, 89(4), 369.

[24]. Weitz, B. A., Sujan, H., \& Sujan, M. (1986). Knowledge, motivation, and adaptive behavior: A framework for improving selling effectiveness. The Journal of marketing, 174-191.

[25]. Tai-Seale, T. \& Thompson, S.B. (2000). Assigned Conversations. College Teaching, 48(1), 15-18

[26]. Messick, D., M. \& Kramer R., M. (2004). Psychology of leadership: some new approached. Lawrence Erlbaum Associates, Incorporated.

[27]. Clough, G. W. et al. (2004). The engineer of 2020: Visions of engineering in the new century. National Academy of Engineering, Washington, DC.

[28]. Yukl, G. A. (2002). Leadership in organizations.

[29]. Smith, P. K., Dijksterhuis, A., \& Wigboldus, D. H. (2008). Powerful people make good decisions even when they consciously think. Psychological Science.

[30]. Goulding, C. (1998). Grounded theory: the missing methodology on the interpretivist agenda. Qualitative Market Research: An International Journal, 1(1), 50-57.

[31]. Dey, I. (1999). Grounding grounded theory: Guidelines for qualitative inquiry. Academic Press.

[32]. Wilson, H. S., \& Hutchinson, S. A. (1996). Methodologic mistakes in grounded theory. Nursing research, 45(2), 122-124.

[33]. Charmaz, K. (2006). Constructing grounded theory: A practical guide through qualitative research. Sage Publications Ltd, London.

[34]. Mills, J., Bonner, A., \& Francis, K. (2006). The development of constructivist grounded theory. International journal of qualitative methods, 5(1), 25-35.

[35]. Edwards, K. E., \& Jones, S. R. (2009). "Putting my man face on": A grounded theory of men's gender identity development. Journal of College Student Development, 50(2), 210-228 